九州大学学術情報リポジトリ

Kyushu University Institutional Repository

\title{
Structural and Physical Characterization of Nanodiamond Composite Thin Films Synthesized by Pulsed-Laser Ablation Method (A Review)
}

OSMAN, LAMA

Department of Applied Science for Electronics and Materials, Kyushu University

ZKRIA, ABDELRAHMAN

Department of Applied Science for Electronics and Materials, Kyushu University

YOSHITAKE, TSUYOSHI

Department of Applied Science for Electronics and Materials, Kyushu University

https://doi.org/10.5109/4738587

出版情報: Proceedings of International Exchange and Innovation Conference on Engineering \& Sciences (IEICES). 7, pp. 190-179，2021-10-21. 九州大学大学院総合理工学府

バージョン:

権利関係 : 


\title{
Structural and Physical Characterization of Nanodiamond Composite Thin Films Synthesized by Pulsed-Laser Ablation Method (A Review)
}

\author{
LAMA OSMAN $^{1 *}$, ABDELRAHMAN ZKRIA $^{1}$, TSUYOSHI YOSHITAKE ${ }^{1}$ \\ ${ }^{1}$ Department of Applied Science for Electronics and Materials, Kyushu University, 6-1 Kasuga-Koen, Kasuga, Fukuoka \\ 816-8580, Japan. \\ *Corresponding author email: osman_lama@kyudai.jp
}

\begin{abstract}
Ultrananocrystalline diamond/hydrogenated amorphous carbon composite (so called Nanodiamond composite) thin films were deposited on diverse substrate materials at optimum substrate temperature of $550^{\circ} \mathrm{C}$ and ambient hydrogen pressure of $53.3 \mathrm{~Pa}$ by pulsed-laser deposition technique. The structural and physical characterization of the undoped, nitrogen-doped and boron-doped films were well-discussed through this review.
\end{abstract}

Keywords: Ultrananocrystalline diamond; Pulsed-laser ablation; XPS; NEXAFS

\section{INTRODUCTION}

Ultrananocrystalline diamond/ hydrogenated amorphous carbon, later called Nanodiamond composite (NDC) films comprise diamond crystallites with less than $10 \mathrm{~nm}$ in diameter within the amorphous carbon matrix are splendid candidates for diverse electronic, optical and biomedical applications as they are grown on various solid-state substrates. NDC films have tremendously smooth surface which is contrastive to that of polycrystalline diamond and high thermal conductivity as well as hardness and bio-compatibility. These unparalleled properties are strongly depending on the numerous grain boundaries (GBs) they comprise [1-3]. On the other hand, conventional common methods such as chemical vapor deposition (CVD) has ever been used intensively to grow nanocrystalline diamond films and their conditions of growth are well defined. However only few researches were conducted by physical vapor deposition techniques. One of the genuine physical vapor deposition facilities is pulsed-laser ablation, or called pulsed-laser deposition (PLD). PLD method utilizes a pulsed laser beam to irradiate a solid target of material to be deposited as a film by generating vapor form of highly energetic species. Frequently, PLD has been conducted broadly for developing high quality thin films of assortment of materials. On contrary to CVD process, physical vapor deposition techniques, including PLD can easily deposit ultrananocrystalline diamond (UNCD) films with high quality and under lower temperatures. Hereby, within this review we summarize and discuss promising features of NDC films synthesized on different substrates by pulsed-laser ablation technique and their optimum deposition conditions. In addition, the structural and physical characterization of the undoped, nitrogen doped and boron doped NDC films were explained based on the results of our research group.

\section{EXPERIMENTAL PROCEDURES}

Early back to 1995 , diamond crystallites impeded into amorphous carbon matrix films in a hydrogen content were grown on Si substrate has been reported by Polo et al. [4]. Four years later Yoshimoto et al. succeeded in growing heteroepitaxial diamond crystallites characterized with several $\mu \mathrm{m}$ on sapphire substrate under oxygen atmosphere [5]

Based on the study of Yoshitake et. al.[6]on diamond like carbon (DLC) growth in 2000 , they have found both of Oxygen and Hydrogen has the selective ability of etching of $s p^{2}$ bonds rather than $s p^{3}$ ones, however ambient oxygen at low pressure is much effective in $s p^{2}$ etching process than ambient hydrogen, that is because oxygen molecules easily interact with atomic carbon but for hydrogen molecules a higher pressure (greater than $10 \mathrm{~m}$ Torr) is required to dissociate them into atomic form under collision with the high energetic carbon species ejected from the target [6]. These findings enlighted their thoughts for optimizing conditions of the heteroepitaxial nucleation and growth of nanodiamond films. In 2001, They optimized conditions of the PLD deposition under Oxygen atmosphere pressure of $5 \times 10^{-2}$ Torr and substrate temperatures vary between $550^{\circ} \mathrm{C} \sim 600^{\circ} \mathrm{C}$ to grew $1-5 \mu \mathrm{m}$ single phase diamond thin film on diamond (100) substrate using ArF excimer laser (Lambda Physik LPX350ST, $193 \mathrm{~nm}, 24 \mathrm{~ns}$ ) and graphite target within 2-4 hours. The distance between the target and substrate holder was set about $20 \mathrm{~mm}$. The laser beam was focused with $45^{\circ}$ with respect to the normal of the rotating target through spherical lens. The $139 \mathrm{~nm}$ incident laser beam at pulse repetition rate of $10 \mathrm{~Hz}$ irradiates about $2 \mathrm{~mm}^{2}$ of the target area with irradiance of $1.5 \times 10^{8} \mathrm{~W} / \mathrm{cm}^{2}$ and fluence of $5 \mathrm{~J} / \mathrm{cm}^{2}[7,8]$. The deposition rate was roughly about $5-10 \mathrm{~nm} / \mathrm{min}$ [9]. Despite the formation of $1 \mu \mathrm{m}$ diamond crystallites thin film by previous conditions and under the oxygen atmosphere, the smoothness of the film surface was quite difficult to be achieved, however hydrogen can be utilized for its surfactant effect and morphology improvement for broad range of materials. In comparison with oxygen, hydrogen has same etching effect of $s p^{2}$ bonds, yet its weak ability requires higher pressures than 1 Torr for the nanocrystalline diamond growth which is two times of magnitude greater than the optimized oxygen pressure. This condition enhances the accumulation of carbon species into nanodiamond crystals in addition to the thermal energy provided by the substrate heater. Hara et al. adapted these conclusions and succeed in growing extremely fine nanocrystalline diamond film with crystallites of 10-20 nm in diameter by PLD but in Hydrogen content pressure of 4 Torr, laser repetition rate of $50 \mathrm{~Hz}$ and under deposition rate of 80 $\mathrm{nm} / \mathrm{min}$. the substrate temperature was maintained at $550^{\circ} \mathrm{C}$ which is less by $150^{\circ} \mathrm{C}$ compared with the CVD method[10].

It was found by investigating growth of nanodiamond films in both ambient oxygen and hydrogen atmosphere the dependence of the diamond growth in case of oxygen on the substrate orientation which is regardless in hydrogen case[11].

In 2006, a $2 \mu \mathrm{m}$ film in thickness of NDC was successfully deposited on (0001) sapphire substrates 
whose dimensions are $17 \times 17 \times 0.43 \mathrm{~mm}$ at temperature of $550^{\circ} \mathrm{C}$ by PLD (Fig.1) in hydrogen pressure of 4 Torr. The deposited film comprised dense non-oriented grains with diameters about $5 \mathrm{~nm}$, Moreover, they are more viable within the central region and gradually decrease in thickness towards the edge of the substrate with respect to the plume center [12].

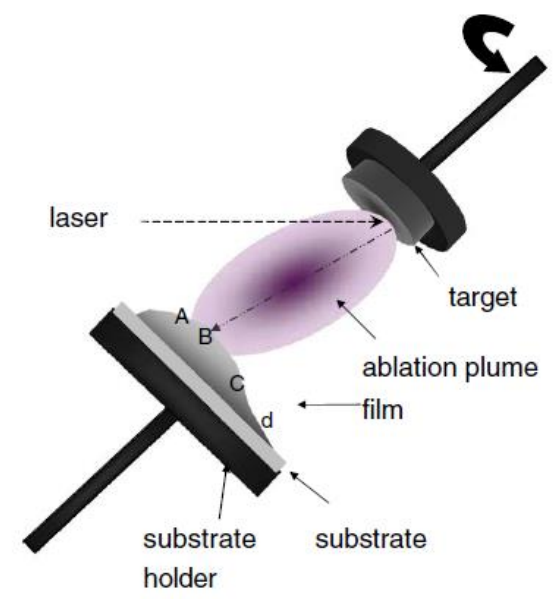

Fig.1. Schematic graph shows mechanism of NDC film growth by PLD method [12].

Three years later, NDC (or NDC) has been deposited by PLD on Si substrates at hydrogen pressure and substrate temperature of $53.3 \mathrm{~Pa}$ and $550^{\circ} \mathrm{C}$ respectively in same preparation manner of previous reports [13].

The structural characterization of NDC films has been investigated using various techniques. Transmission electron microscopy (TEM) has been applied to confirm the growth of NDC crystallites [14]. While the optical properties of the grown NDC films were studied by determining their direct and indirect optical spectra. Raman spectroscopy was employed to emphasize the NDC existence within the a-C matrix Moreover, the chemical bonding configuration of the NDC films has been conducted by Fourier transform infrared spectroscopy (FTIR), X-ray photoemission spectroscopy (XPS) and Near-Edge X-ray absorption fine structure (NEXAFS) with the aid of synchrotron radiation of SAGA light source at beamline 12. A sample reference of highly oriented pyrolytic graphite was set to calibrate energy. NEXAFS spectra has been taken in total electron yield mode through determining the current flow from the sample to the ground $[13,15]$.

\section{RESULTS AND DISCUSSION}

The structure of Nanodiamond composite (NDC) films were evaluated using TEM examinations in dark-field mode as shown in (Fig.2) as well as the included selected area electron diffraction rings, the films preparation for the TEM observation were performed by focused ion beam (FIB)[14]. The selected area diffraction rings are formed due to diamond (111), (220) and (311) with no evidence of graphite rings. It is clear from the dark field - TEM image taken from part of the diamond (111) diffraction ring, that NDC crystallites are observed as flecks and are $5 \mathrm{~nm}$ in diameter in the amorphous carbon matrix. These NDCs are apparently not oriented and their sizes as well as their densities are independent from the film thickness[13]. The dark and light contrast arises from the fact of the surrounding a-C matrix and not according to altering of the tilt angle of the irradiant electron beam.

\subsection{Hydrogenated NDC/a-C films}

A high resolution TEM image (Fig.3) shows separating distance of $0.21 \mathrm{~nm}$ between the sequent fingers generated from diamond (111). The variant contrast refers to the density distribution of the NDCs among the a-C matrix which highly dependent on the bombardment of the incident ion beam[12].

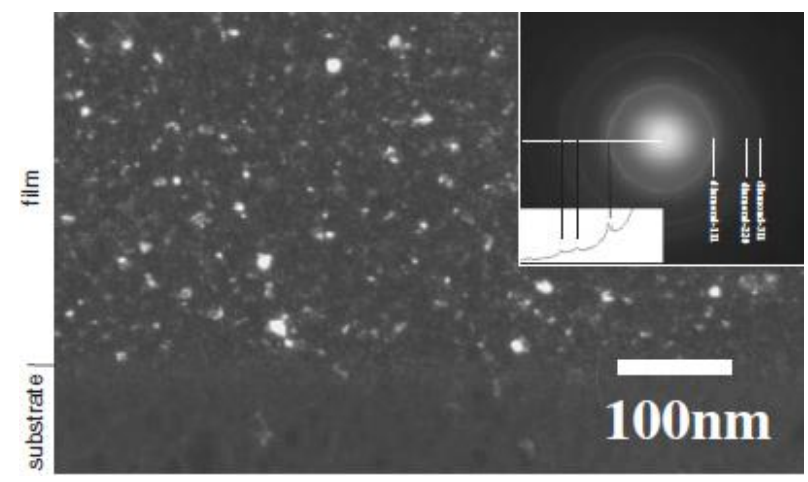

Fig. 2. Dark field TEM photograph of partial diamond (111) ring in NDC films. Inset is the selected area electron diffraction rings [13].Copyright (2021) The Japan Society of Applied Physics.

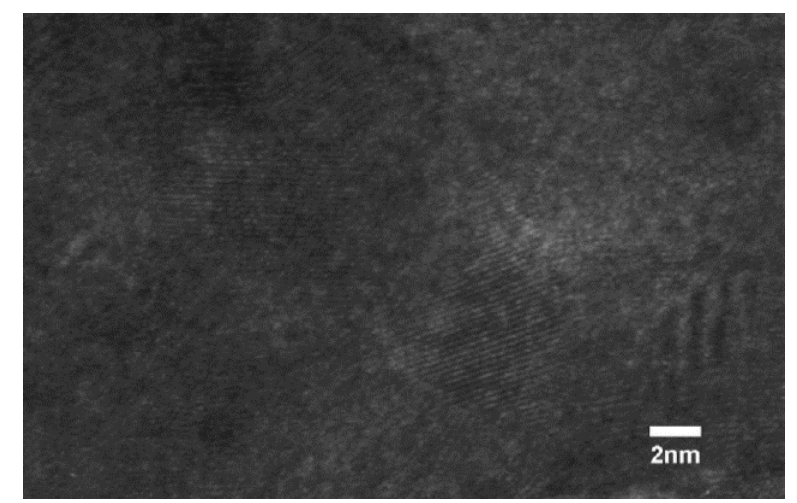

Fig. 3. High-resolution TEM photograph of NDC film [12].

Using the obtained transmittance $(\mathrm{T})$ and reflectance $(\mathrm{R})$ as well as the NDC film thickness ( $\mathrm{t}$ ), the absorption coefficient $(\alpha)$ can be determined by the following equation[16]

$$
\alpha=\frac{2 \ln (1-R)-\ln T}{t}
$$

As shown in (Fig.4) the optical absorption coefficient spectrum is given for NDC, a-C and DLC films. The optical absorption coefficient $(\alpha)$ of the NDC film is about $10^{-6} \mathrm{~cm}^{-1}$ at photon energies between 3 to $5 \mathrm{eV}$. This value is four times greater than the given for diamond[17]. In the same regard, it is also the largest among the $(\alpha)$ values of the a-C film deposited in vacuum at $550^{\circ} \mathrm{C}$ and DLC film deposited in same hydrogen pressure $53.3 \mathrm{~Pa}$ at room temperate. 


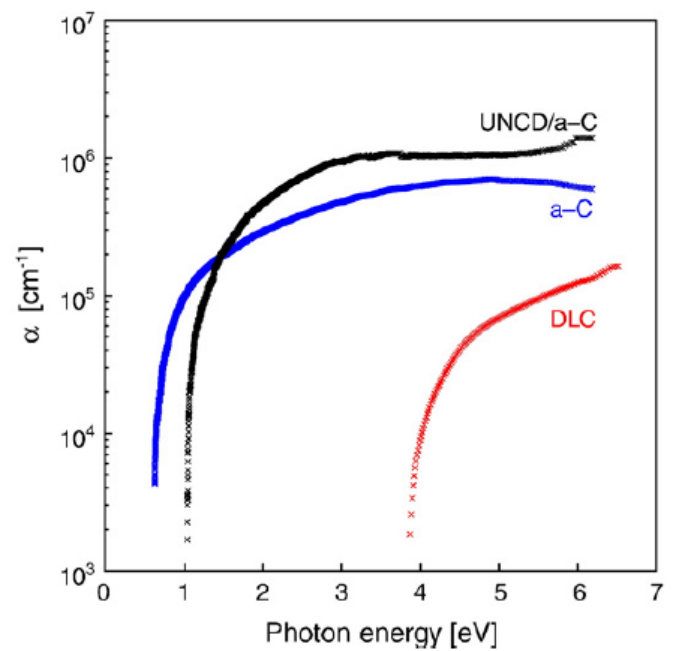

Fig.4. The optical absorption spectrum of the NDC, a-C film, and DLC films [18].

The direct and indirect optical band gaps of the NDC film are $2.2 \mathrm{eV}$ and $1.0 \mathrm{eV}$ as evaluated from the interpolation of the $(\alpha h v)^{2}$ and $(\alpha h v)^{1 / 2}$ curves against photon energy (hv) respectively (Fig.5) Since the a-C films with blended $s p^{3}$ sand $s p^{2}$ bonds have indirect optical band gap values varies from 0 to $5 \mathrm{eV}$ corresponding to $s p^{3}$ and $s p^{2}$ ratio, it is believed that a- $\mathrm{C}$ matrix is the responsible for the obtained $1.0 \mathrm{eV}$ indirect optical band gap value of the NDC film.

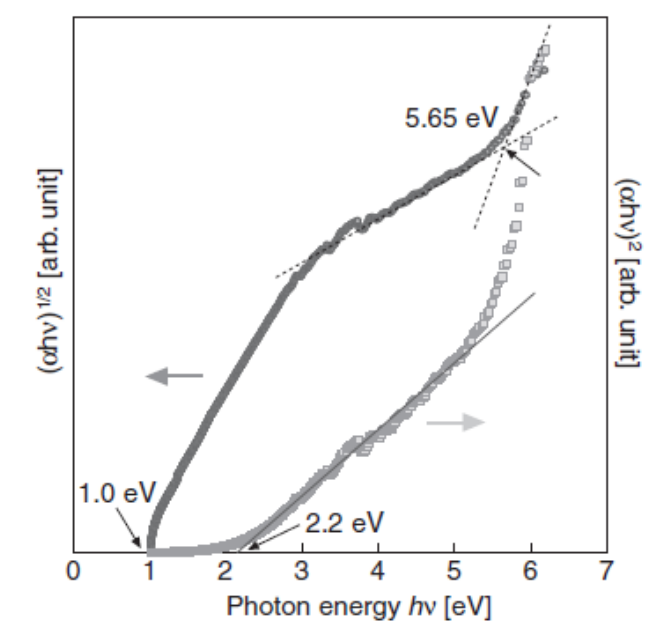

Fig. 5. Optical absorption spectrum of $(\alpha h v)^{2}$ and $(\alpha h v)^{1 / 2}$ against photon energy $(h v)$ for the NDC film [14].

On the other hand, the measured band gap of the direct optical band gap $2.2 \mathrm{eV}$ is distinguishing for the NDC composite. This considerable optical absorption from 2.2 to $5.4 \mathrm{eV}$ is attributed to the grain boundaries between NDC crystallites themselves and with a-C matrix in the NDC films which is in coincidence with the theoretical prediction of the formation of energy state in diamond band gap due to the NDCs grain boundaries [19].The appearance of band edge at $5.4 \mathrm{eV}$ corresponding to diamond is another confirmation of the NDCs formation[14, 18].

Visible Raman spectra of the formed NDC film are presented in (Fig.6) the film shows intensive G and D peaks corresponding to the a-C matrix while only a wide weak peak at $1149 \mathrm{~cm}^{-1}$ is characteristic for NDCs. This specific peak not shown for the a-C and DLC films. It was theoretically expected that dangling bonds of carbon clusters terminated by hydrogen prefers tetrahedral structure specific for NDCs growth[20]. That's why hydrogen is indispensable in NDC formation by pulsedlaser ablation.

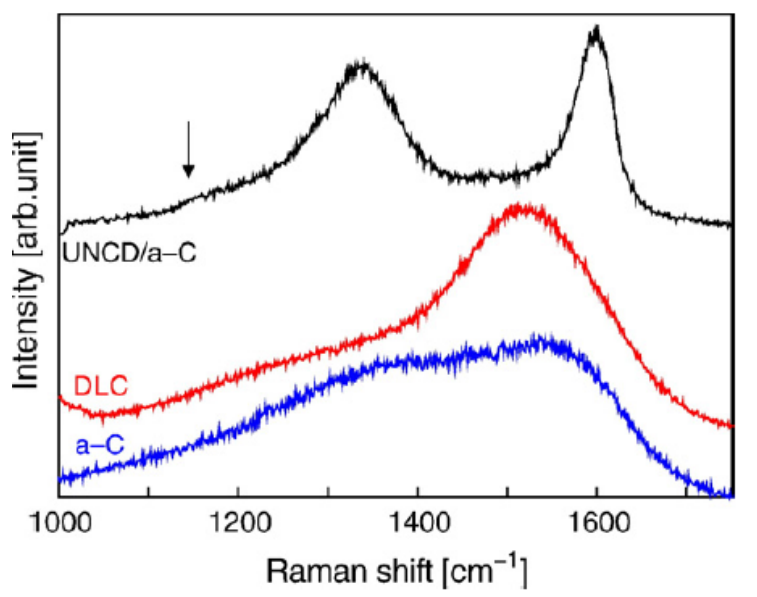

Fig. 6. Visible Raman spectra of NDC film grown at $550{ }^{\circ} \mathrm{C}$ and hydrogen pressure of $53.3 \mathrm{~Pa}$, DLC film grown at room temperature in 53.3 Pa hydrogen and a-C film grown at $550{ }^{\circ} \mathrm{C}$ in vacuum [18].

Although Raman spectroscopy was broadly utilized for studying carbon-based materials, it has a lot of disadvantages that limits its usage. For instance, the cross-section of Raman spectroscopy to $s p^{2}$ bonds is 50 orders of magnitude more than $s p^{3}$ bonds which contribute to more sensibility to graphite than diamond. Moreover, the detection of NDC crystallites of wide range distribution of sizes strongly depends on the wavelength of the incident beam. Ultraviolet incident beam is inevitable in such case. These drawbacks fortunately can be avoided by employing (XPS) and (NEXAFS)[15, 21].

The growth of NDC crystallites was confirmed by X-ray photoemission, NEXAFS and FTIR spectroscopies. For comparison the investigation was conducted on NDC, a$\mathrm{C}: \mathrm{H}$, and a-C films of same thickness $(100 \mathrm{~nm})$ [13].

$\mathrm{X}$-ray photoemission spectroscopy is an effective technique for estimating the $s p^{3} / s p^{2}$ ratio in the films [22] wherein they coexist as NDCs and amorphous carbon matrix. Furthermore, employing synchrotron radiation with a monochromatic intense and high accurate beam enhances the measurement. This technique probes chemical bonding structures in the vicinity of the film surface through measuring the ejected photoelectrons from the $\mathrm{C} 1 \mathrm{~s}$ core level. For broad range evaluations, a $\mathrm{Mg} \mathrm{K} \alpha$ line with photon energy of $1253.6 \mathrm{eV}$ was applied simultaneously. The etchant Ar ion beam was applied with $1 \mathrm{kV}$. (Fig.7) reveals the obtained photoemission spectra of NDC film dependently on the $\mathrm{Ar}$ ions bombardment time with intensive $\mathrm{O} 1 \mathrm{~s}$ and $\mathrm{C} 1 \mathrm{~s}$ peaks at $532 \mathrm{eV}$ and $284 \mathrm{eV}$ respectively. It is obviously that the $\mathrm{O} 1 \mathrm{~s}$ peak instantly vanish away after the exposure to Ar ions bombardment which evidently related only to the film surface[15]. 


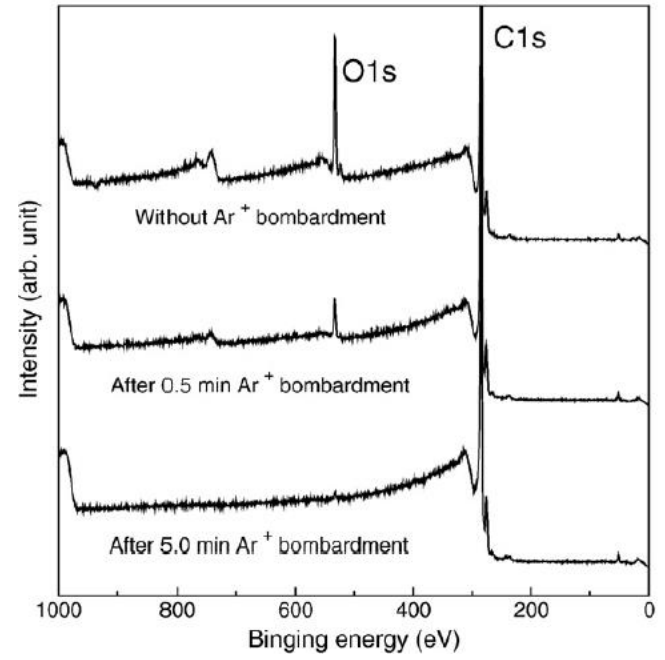

Fig.7. X-ray photoemission spectra of NDC films for argon ion bombardment at different exposure times [15].

For proper understanding of the chemical bond's configuration of NDC film grown at substrate temperature $550{ }^{\circ} \mathrm{C}$ and hydrogen pressure of $53.3 \mathrm{~Pa}$, a$\mathrm{C}$ film deposited at same substrate temperature $550{ }^{\circ} \mathrm{C}$ but in vacuum, and a-C:H film deposited at room temperature and hydrogen pressure of $53.3 \mathrm{~Pa}$, their $\mathrm{C} 1 \mathrm{~s}$ photoemission spectra was evaluated by synchrotron radiation as shown in (Fig.8) without argon ions etching. The outcome XPS spectra was decomposed into subcomponents according to $\mathrm{CO} / \mathrm{C}-\mathrm{O}-\mathrm{C}, \mathrm{C}=\mathrm{O} / \mathrm{COOH}$, $\mathrm{C}=\mathrm{O}, \quad s p^{2}$ and $s p^{3}$ bonds employing Voigt functions while the background was subtracted using Shirley's method [23]. The $s p^{3} /\left(s p^{2}+s p^{3}\right)$ ratio for the three films was measured from the area under the $s p^{2}$ and $s p^{3}$ peaks of each film [24] and were found to be 68, 66 , and $61 \%$ for the NDC, a-C and a-C:H films respectively. Clearly, the NDC composes the largest $s p^{3} /$ $\left(s p^{2}+s p^{3}\right)$ ratio among them which returns to the large amount of NDC crystallites it comprises. This value also greater than the obtained from NDC films deposited by chemical vapor deposition [25] wherein extensively dense NDCs are impeded in the a-C:H matrix [13]. In hydrogenated amorphous carbon films, the $s p^{3}$ bonding amount was found to be heavily correlated to the film growth technique [26]. This explains the large $s p^{3}$ content proposed by a-C and a-C:H films fabricated by PLD without NDC crystallites content as well as their large contribution in NDC films prepared by PLD in comparison with their counterpart prepared by CVD due to their different a-C matrices[15].

The calculated full width at half maximum from the $s p^{3}$ peak of NDC film was found about $0.91 \mathrm{eV}$ which is quite less than the obtained from a-C $1.04 \mathrm{eV}$ and a-C:H films $1.06 \mathrm{eV}$. This sharp $s p^{3}$ peak of the NDC film was attributed to the large presence of NDC crystallites as the wave function near the Fermi level is more homogenous in crystallites than in amorphous structures[27].

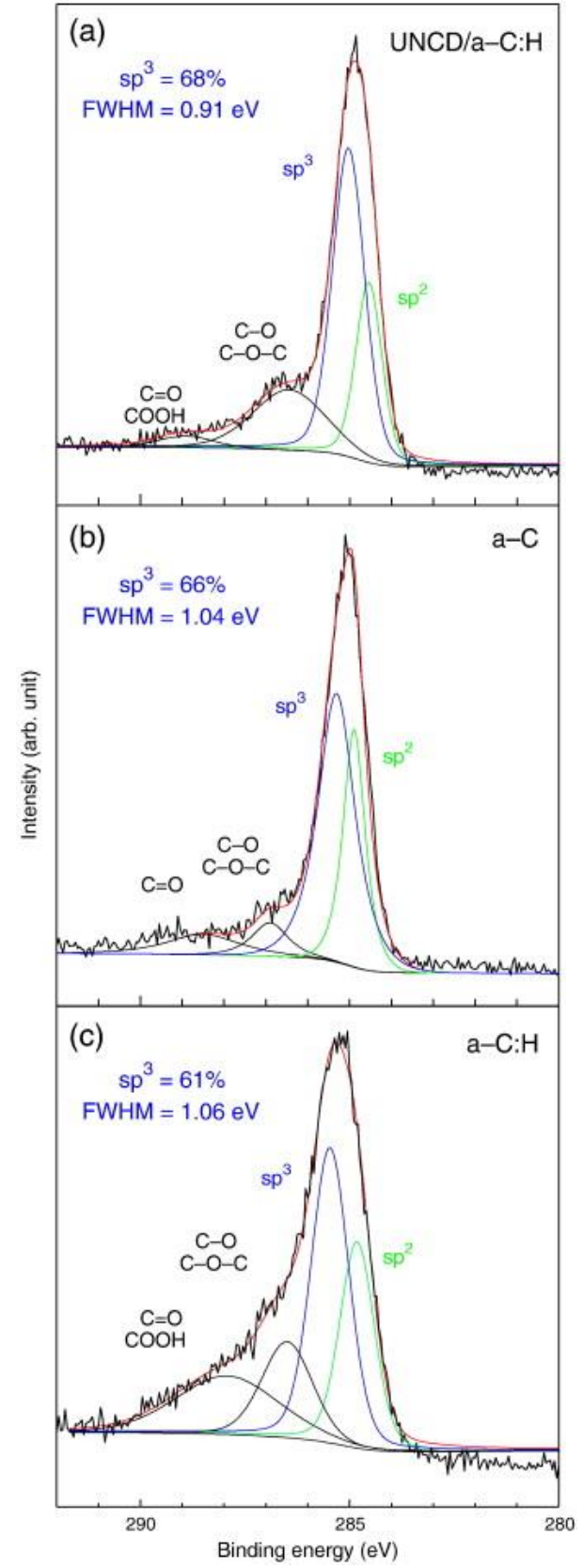

Fig. 8. X-ray photoemission spectrum of (a) NDC (b) a$\mathrm{C}$ and (c) a-C:H films [15].

FTIR spectroscopy was measured for the NDC film deposited at $550^{\circ} \mathrm{C}$, a-C: $\mathrm{H}$ film deposited at room temperature and a-C film deposited at $550^{\circ} \mathrm{C}$ in vacuum to examine the $\mathrm{CH}_{\mathrm{n}}(\mathrm{n}=1,2$ and 3) bonds in the films as clear in (Fig. 9) (a) and (b) given for NDC and a-C:H films without any clue for $\mathrm{CH}_{n}$ peaks of the a-C film. As the obtained spectra is a superposition of various $\mathrm{CH}_{n}$ vibration peaks it was decomposed into component peaks corresponding to Gaussian function. No difference in the spectra between NDC and a-C:H films was noticed except for $s p^{3}-\mathrm{CH}$ peak appeared at $2900 \mathrm{~cm}^{-1}$. NDC film reveals intense $s p^{3}-\mathrm{CH}$ peak which is relevant to the unique grain boundaries of NDCs terminated by hydrogen atoms as well as the a-C:H matrix despite the elevated temperature of deposition [13]. 


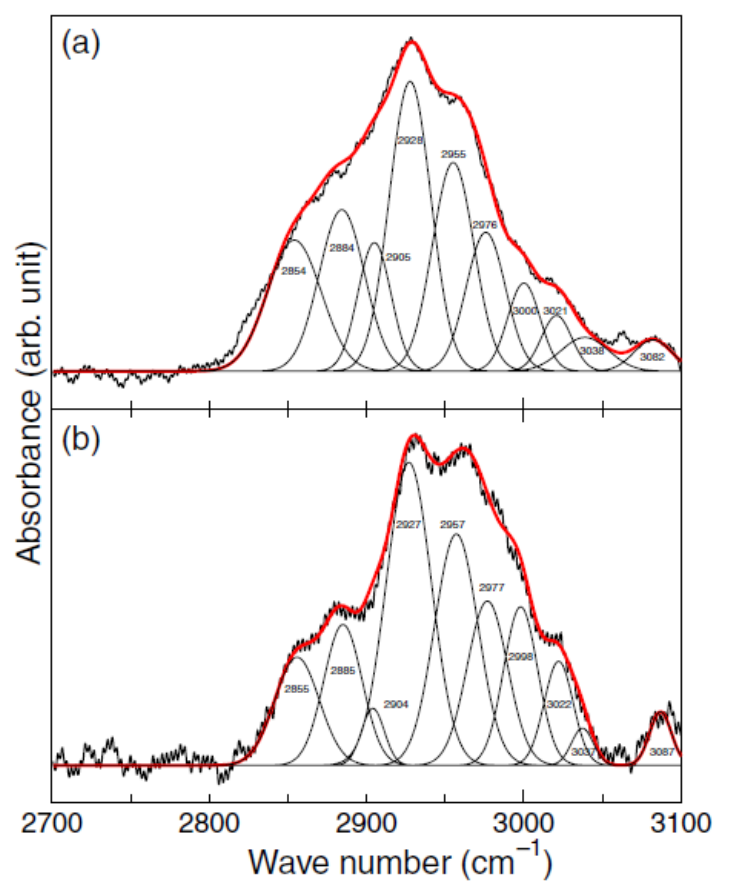

Fig.9. FTIR of (a) NDC films grown at $550^{\circ} \mathrm{C}$ with hydrogen pressure of 53.3 $\mathrm{Pa}$ and (b) a-C:H films grown at room temperature with a hydrogen pressure of $53.3 \mathrm{~Pa}$ [13]. Copyright (2021) The Japan Society of Applied Physics.

As NDC films have convoluted structure comprising the grain boundaries responsible for the marvelous physical properties of NDC films, their atomic bonding configuration is properly investigated by NEXAFS spectra. This technique utilizes the ultimate wave function in the vicinity of the excited atom resulting from $\mathrm{C} 1 \mathrm{~s}$ core shell transition to higher unoccupied states due to X-ray photon absorption. The prevailing interactions could be attributed to the localized bonds and the outcome NEXAFS spectra is decomposed into simple component spectra [22, 28] NEXAFS spectra were measured for NDC film fabricated at $550^{\circ} \mathrm{C}$ and hydrogen content pressure of $53.3 \mathrm{~Pa}$, a-C film fabricated in vacuum at substrate temperature of $550^{\circ} \mathrm{C}$ and a-C: $\mathrm{H}$ film fabricated at room temperature and hydrogen pressure of 53.3 Pa. The intensity of these spectra was normalized at photo energy of $330 \mathrm{eV}$. Two essential peaks were observed at $285 \mathrm{eV}$ and the other between 290 and $295 \mathrm{eV}$ due to $\pi^{*}$ and $\sigma^{*}$ bonding structure respectively while within photo energies between 285 and $290 \mathrm{eV}$ differences among the spectra revealed the superposition of assorted peaks. The $s p^{2}$ bonding fractions were found to be $58 \%, 67 \%$, and $40 \%$ for the NDC/a- C:H, a-C and a-C:H films respectively using the below equation

$$
f_{s p^{2}}=\frac{I_{s a m}^{\pi^{*}} I_{r e}(\Delta E)}{I_{r e f}^{\pi^{*}} I_{s a m}(\Delta E)}
$$

Where $I_{\text {sam }}^{\pi^{*}}$ and $I_{\text {ref }}^{\pi^{*}}$ represent areas under $\pi^{*}$ peaks for the samples and the reference HOPG material respectively while $I_{r e}(\Delta E)$ and $I_{\text {sam }}(\Delta E)$ are the rest areas under each spectra of the films within the range [288.6eV 315eV]. Despite the room temperature deposited a-C:H film reveals the less $s p^{2}$ bonding fraction, NDC has less $s p^{2}$ bonding fraction than a-C film deposited in the same elevated temperature which obliviously characteristic for the NDC grain in NDC film. The overall NEXAFS spectra from the constituent peaks is shown by the red line in (Fig.10) An error step function was employed to fit the jump in the $\mathrm{C} \mathrm{k}$-edge at ionizing potential while the remained spectra is fitted into Gaussian peaks [29]. for identical materials, the peak profile is unchangeable because they are responsible for the wave function. Additionally, the peak profile of the decomposed spectra must be uniform with fixed position as the length of the bonds of same based materials not divergent.

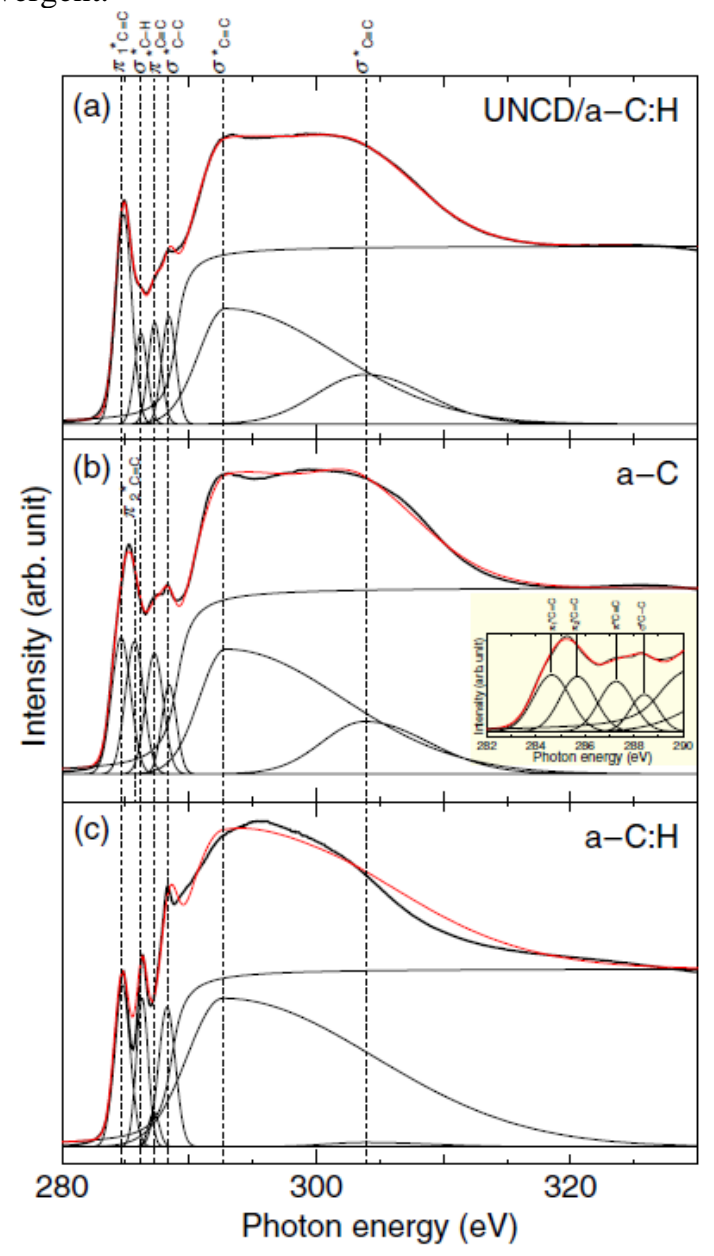

Fig.10. NEXAFS spectra of (a) NDC films fabricated at $550^{\circ} \mathrm{C}$ and hydrogen pressure of $53.3 \mathrm{~Pa}$, (b) a-C films fabricated at $550^{\circ} \mathrm{C}$ in vacuum, and (c) a-C:H films deposited at room temperature and hydrogen pressure of 53.3 Pa. The included set in (b) is a magnified spectrum [13]. Copyright (2021) The Japan Society of Applied Physics.

These component spectra were fitted due to $\pi^{*} \mathrm{C}=\mathrm{C}, \pi^{*} \mathrm{C} \equiv \mathrm{C}, \sigma^{*} \mathrm{C}-\mathrm{H}, \sigma^{*} \mathrm{C}-\mathrm{C}, \sigma^{*} \mathrm{C}=\mathrm{C}$ and $\sigma^{*} \mathrm{C} \equiv \mathrm{C}$. A$\mathrm{C}$ film shows broad $\pi^{*} \mathrm{C}=\mathrm{C}$ peak than the other films. This peak was decomposed into two constituent peaks as clarified in the included set of (Fig.10) which indicated the coexistence of two various lengths of bonds in a-C film. A comparison between NDC and a-C films reveals two differences in their spectra, one of them turns to the appearance of $\sigma^{*} \mathrm{C}-\mathrm{H}$ in the expense of weakening $\sigma^{*} \mathrm{C} \equiv \mathrm{C}$ peak due to hydrogen termination while the other in the intense $\sigma^{*} \mathrm{C}-\mathrm{C}$ peak, NDC film shows with respect to its counterpart in a-C film which is origin for the existence of the NDC crystallites. On the other hand, the NDC film deposited on $550^{\circ} \mathrm{C}$ has intensive $\pi^{*} \mathrm{C} \equiv \mathrm{C}$ and 
$\sigma^{*} \mathrm{C} \equiv \mathrm{C}$ peaks than the a-C:H film deposited in room temperature implying the enhancement of the $\mathrm{C} \equiv \mathrm{C}$ bonds in high temperatures. Furthermore, the deposited a-C:H film in room temperature is associated with a strong $\sigma^{*} \mathrm{C}$ $\mathrm{H}$ peak in comparison with NDC film deposited at high temperature due to the enhanced hydrogen content as well as a strong $\sigma^{*} \mathrm{C}-\mathrm{C}$ peak instead of $\mathrm{C} \equiv \mathrm{C}$ peak which is selectively formed $[13,21]$.

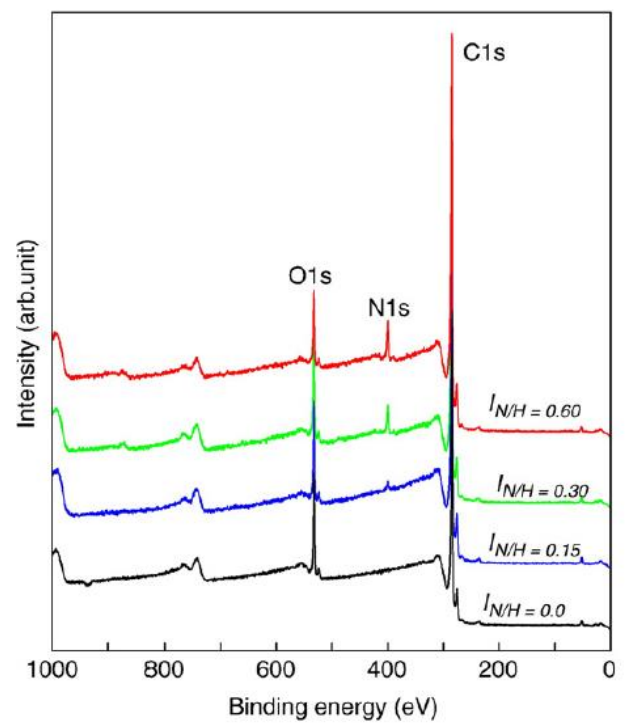

Fig.11. X-ray photoemission spectrum of NDC films formed at different inflow [30].

\subsection{Nitrogen-doped NDC films}

$\mathrm{X}$-ray photoemission spectra with Mgka line measured for nitrogen-doped NDC films (Fig.11) with different inflow ratios of $I_{N / H}$ comprises N1s peak whose intensity increased with the increase in the $I_{N / H}$ ratio. It was not adversely affected by the Ar ions etching [30].

For various inflow ratios $I_{N / H}$ of $0.0,0.15,0.33$ and 0.6 the nitrogen content in the films was estimated as $0,1.6$, $5.4,7.9$ atm. \% respectively [31].

Since the O1s peak was faded as soon as the Ar ion etching took place, the presence of oxygen peak could barely influence the nitrogen concentration in the NDC film [32]. Based on these findings, nitrogen atoms incorporation into NDC films during deposition was realized and its concentration is well managed through inflow ratios $I_{N / H}$ [30].

$\mathrm{C} 1 \mathrm{~s}$ photoemission spectra of the films with nitrogen doping with 7.9 atm. $\%$ and 1.6 atm. $\%$, and 0 atm. $\%$ concentrations is given by (Fig.12) respectively. The spectra were decomposed into components are previously mentioned undoped NDC/a-C: $\mathrm{H}$. The whole films shared the same FWHM value $0.91 \mathrm{eV}$ of $s p^{3}$ peaks distinguished for NDC films which confirms the presence of the NDC crystallites in the films without influence by the nitrogen dopant. Additional $\mathrm{C}-\mathrm{N}$ and $\mathrm{C}=\mathrm{N}$ peaks appeared in the photoemission spectra and were attributed to the incorporation of nitrogen atoms into the grain boundaries which already has been theoretically anticipated [19]. Furthermore, an increase in the $s p^{2}$ bonds amount was reported with the increase in nitrogen content which is reflected on the $s p^{3} /$ $\left(s p^{2}+s p^{3}\right)$ ratio reduction from $68 \%$ to $60 \%$ corresponding to nitrogen concentration from vacuum to 7.9 atm. \% [30].
C K-edge of NEXAFS spectra was obtained for 7.9 atm.\% nitrogen doped NDC film as well as the fitted peaks (Fig.13) and evaluation method of $s p^{3}$ fraction through the previously mentioned procedures. The included set to (Fig.13) is for the nitrogen doping concentrations of $7.9 \mathrm{~atm} . \%$ and $5.4 \mathrm{~atm} . \%$ while the $s p^{2}$ fraction was calculated to increase from $58 \%$ of the undoped to $69 \%$ of the $7.9 \mathrm{~atm} . \%$ nitrogen doped NDC film. This increase is due to the incorporation of nitrogen atoms into the film which decrease the NDC grain sizes and enhance the grain boundaries content which proportionally add to $s p^{2}$ fraction.

In addition to the previous NEXAFS peaks measured for the undoped NDC film, there are three distinctive promoted $\pi^{*} \mathrm{C}=\mathrm{N}, \sigma^{*} \mathrm{C}=\mathrm{N}$ and $\sigma^{*} \mathrm{C}-\mathrm{H}$ peaks at 286.22, 297.8 [33] and 289.2 eV[34] respectively for the $7.9 \mathrm{~atm} . \%$ nitrogen doped NDC film. The presence of $\pi^{*} \mathrm{C}=\mathrm{O}$ or $\sigma^{*} \mathrm{C}-\mathrm{H}$ peaks isn't regarded because they are correlated to contamination which isn't the case for the film deposition. The spectra were classified into two $\pi^{*}$ and $\sigma^{*}$ areas. $\pi^{*}$ area comprises $\mathrm{N}_{\mathrm{a}}, \mathrm{N}_{\mathrm{b}}$, and $\mathrm{N}_{\mathrm{c}}$ peaks at $398.5,400$ and $401.5 \mathrm{eV}$ due to $\mathrm{C}=\mathrm{N}, \mathrm{C}-\mathrm{N}$ bonds and aromatic rings formation by nitrogen atoms incorporation respectively. It was found that $\mathrm{N}_{\mathrm{b}}$ peak due to $\mathrm{C}-\mathrm{N}$ bonds didn't sharpen with the increase in the nitrogen content but otherwise it is weakened in the same regard for graphitic carbon nitride [35], the reason why no $\mathrm{C} \equiv \mathrm{N}$ bonds were observed [36].

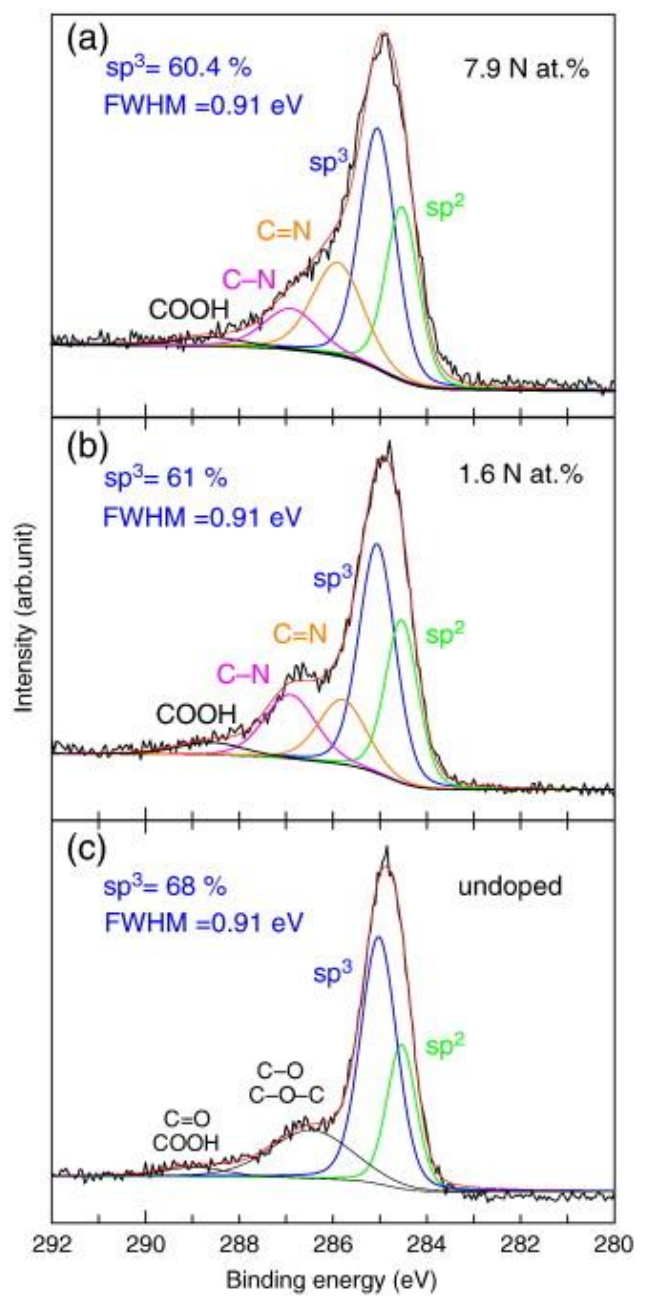

Fig.12. C1s X-ray photoemission spectra of (a) 7.9 atm. \% nitrogen doped (b) $1.6 \mathrm{~atm} . \%$ nitrogen doped and (c) undoped NDC films [30]. 


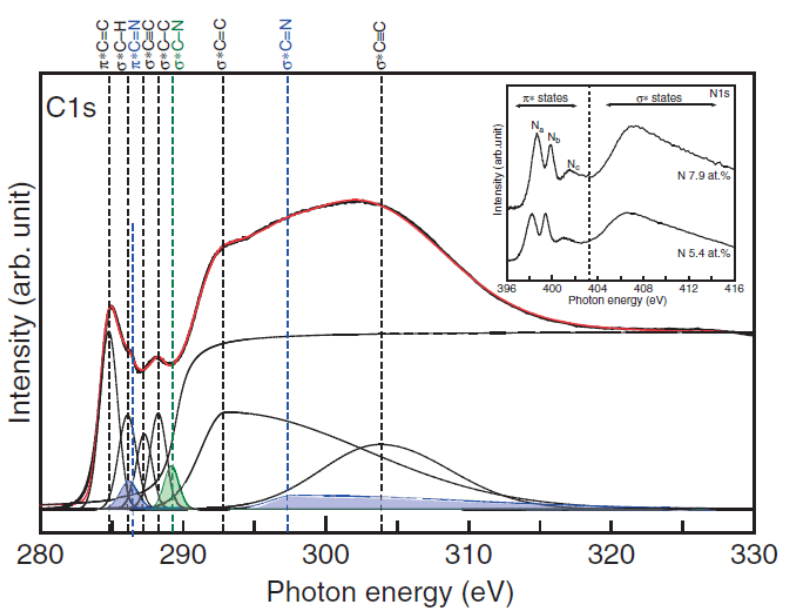

Fig.13. C K-edge NEXAFS spectra of 7.9 atm.\% nitrogenated NDC film. The included set shows $\mathrm{N} \mathrm{K}$ edge NEXAFS spectrum of the $7.9 \mathrm{~atm} . \%$ and $5.4 \mathrm{~atm} . \%$ nitrogenated NDC films [36].

\subsection{Boron-doped NDC films}

C 1s X-ray photoemission spectroscopy spectra of the undoped $3 \mathrm{~atm} . \%$ and $13 \mathrm{~atm} . \%$ boron doped NDC films is given by (Fig.14) respectively. the obtained spectra were fitted into peak components due to $\mathrm{CO} / \mathrm{C}$ $\mathrm{O}-\mathrm{C}, \mathrm{C}=\mathrm{O} / \mathrm{COOH}, \mathrm{C}=\mathrm{O}, s p^{2}$ and $s p^{3}$ bonds by Voigt functions and the background was subtracted employing Shirley's method as previously detailed. The $s p^{3} /$ $\left(s p^{2}+s p^{3}\right)$ ratio was found as $68 \%, 69 \%$ and $74 \%$ for the undoped, $3 \mathrm{~atm} . \%$ and $13 \mathrm{~atm} . \%$ boron doped NDC films. The enhancement of $s p^{3}$ bonding fraction is confirmed with the progressive increase in boron content which expand the NDC crystallites in size. Boron incorporation was reported to

decrease the $s p^{3}$ bonding content in a-C:H films thus, no contribution from the a-C:H matrix is expected in boosting the $s p^{3} /\left(s p^{2}+s p^{3}\right)$ ratio. FWHM of the $s p^{3}$ peaks were $0.91 \mathrm{eV}$ for the undoped NDC film while were 0.98 $\mathrm{eV}$ for the 3atm.\% and 13 atm.\% boron doped films simultaneously. These values are clearly smaller than the estimated FWHM values for hydrogenated $(1.04 \mathrm{eV})$ and nonhydrogenated $(1.06 \mathrm{eV}) \mathrm{a}-\mathrm{C}$ films. The numerous NDC grains are responsible for the sharp $s p^{3}$ peak in the NDC films because the wave function is homogenous for the NDC crystallites rather than the amorphous films.

(Fig.15) shows C k-edge NEXAFS spectra for the undoped as well as $3 \mathrm{~atm} . \%$ and $13 \mathrm{~atm} . \%$ boron doped NDC films respectively. the $\sigma^{*} \mathrm{C}-\mathrm{C}$ peak sharpened steadily with the increase in boron atoms incorporation into the film. This increase is attributed to the enlarged NDC grain sizes which enhances the $s p^{3}$ bonds content. However, the position of this peak is a little bit shifter towards largest photon energies arising from the variant bonding length converging to bulk diamond lattice constant. In addition, an enhanced peak corresponding to $\sigma^{*} \mathrm{C}-\mathrm{B}$ bond was regarded due to boron atoms incorporation into the film which neither affect the NEXAFS spectra profiles nor originating from NDC grains but rather from the substitution of hydrogen atoms that terminate dangling bonds giving rise to weaken $\sigma^{*} \mathrm{C}$ $\mathrm{H}$ peak [37].

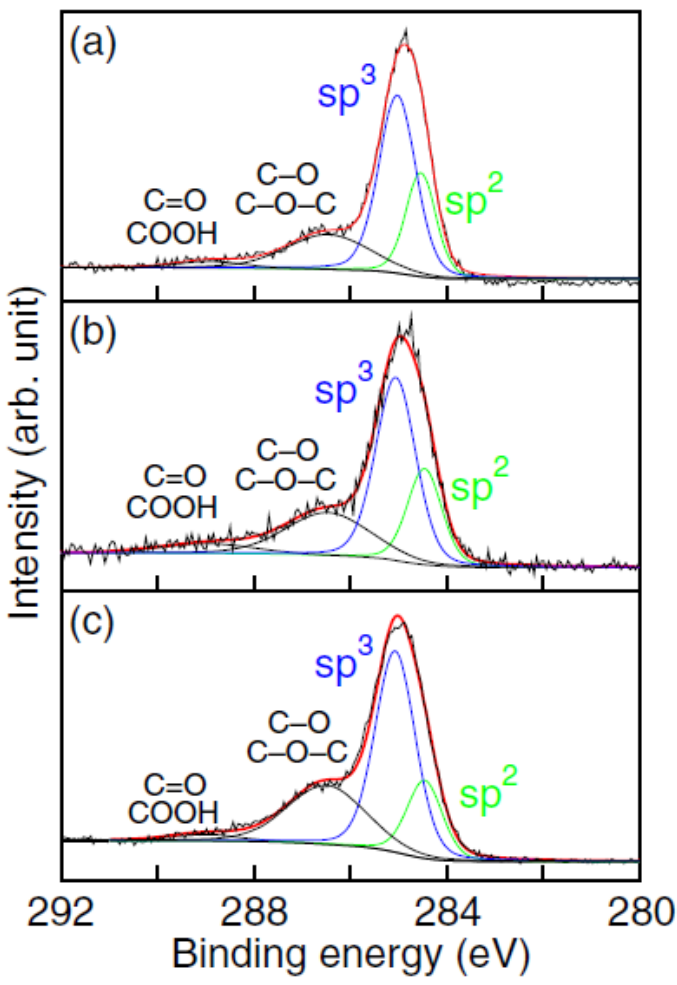

Fig.14. C 1s X-ray photoemission spectroscopy spectrum of (a) undoped (b) $3 \mathrm{~atm}$. \% and (c) $13 \mathrm{~atm} . \%$ boron doped NDC films [37]. Copyright (2021) The Japan Society of Applied Physics.

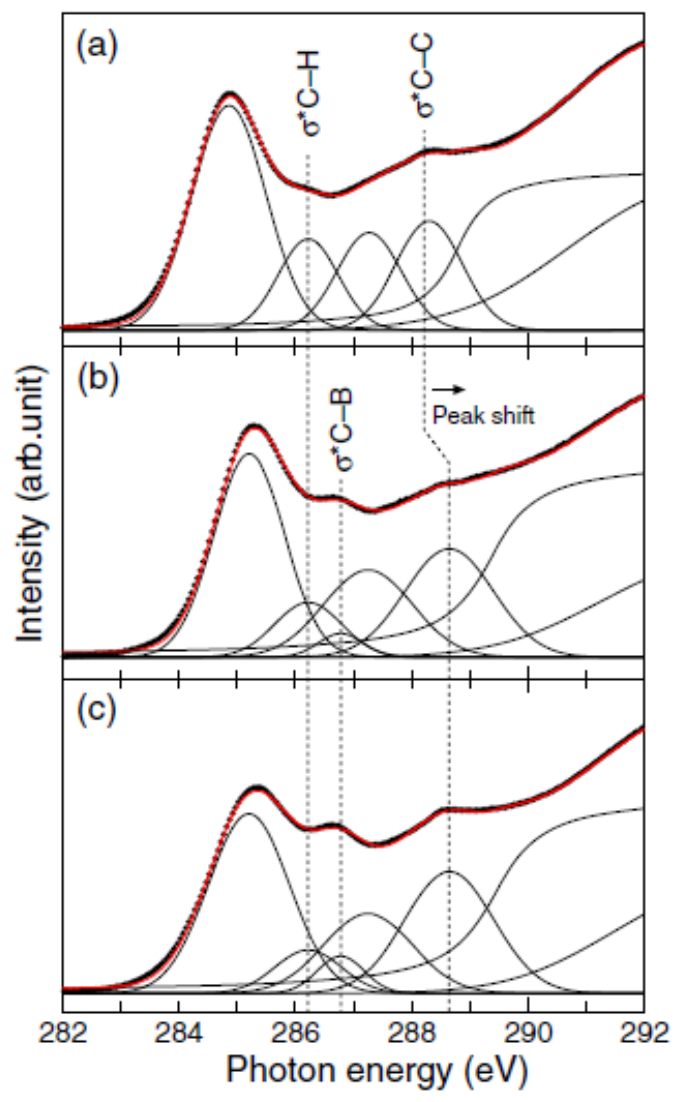

Fig. 15. NEXAFS C K-edge spectrum of (a) undoped, (b) $3 \mathrm{~atm} . \%$ and (c) $13 \mathrm{~atm} . \%$ boron doped NDC films [37]. Copyright (2021) The Japan Society of Applied Physics. 


\section{Conclusion}

In this review, we are systematically discussed three types (Undoped, nitrogen-doped and boron-doped) of ultrananocrystalline diamond/hydrogenated amorphous carbon films (NDC), so called Nanodiamond composite (NDC) films fabricated on different substrates at $550^{\circ} \mathrm{C}$ and ambient hydrogen pressure of $53.3 \mathrm{~Pa}$ by pulsedlaser ablation technique. A large direct band gap optical absorption coefficient of $2.2 \mathrm{eV}$ was reported. The FWHM of the $s p^{3}$ peaks were found to be $0.91 \mathrm{eV}$ for the undoped NDC film as well as the $7.9 \mathrm{~atm} . \%$ nitrogen doped NDC film, while it was $0.98 \mathrm{eV}$ for the $3 \mathrm{~atm} . \%$ boron- doped film. These values were confirmed through NEXAFS evaluations and were smaller than the estimated FWHM values for hydrogenated $(1.04 \mathrm{eV})$ and nonhydrogenated $(1.06 \mathrm{eV})$ amorphous carbon films which were attributed to the large grain boundaries of NDC films within the amorphous carbon matrix. The review explained the advantages of the employed PLD technique as one of advanced physical vapor deposition methods for the growth of Nanodiamonds composite films.

\section{References}

1. Zkria, A., et al., Current Applied Physics, 2019. 19.2 :143-148.

2. Ali, A.M., et al. , Surface and Coatings Technology 2021. 417 : 127185.

3. Ohmagari, S., et al. , Japanese Journal of Applied Physics 2012. 51 :090123.

4. Polo, M.C., et al. , Applied physics letters 1995. 67.4 : 485-487.

5. $\quad$ Yoshimoto, M., et al. , Nature 1999. 399.6734 : 340-342.

6. Yoshitake, T., et al. , Diamond Related. Mater, 2000. 9, pp. 689-692.

7. Yoshitake, T., et al. , Japanese Journal of Applied Physics, 2001. 40.6A : L573.

8. Yoshitake, T., et al. , International Journal of Modern Physics 2002. B 16.06n07 : 825-829.

9. Yoshitake, T., et al. , Applied surface science 2002. 197 : 352-356.

10. Hara, T., et al. , Diamond and related materials 2004. 13.4-8 : 679-683.

11. Hara, T., et al. , Diamond and related materials, 2004. 13.4-8 : 622-626.

12. Hara, T., et al. , Diamond and related materials 2006. 15.4-8 : 649-653.

13. Yoshitake, T., et al. , Japanese Journal of Applied Physics 2009. 48.2R : 020222.

14. Yoshitake, T., et al. , Japanese Journal of Applied Physics 2007. 46.10L : L936.

15. Ohmagari, S., et al. , Diamond and related materials 2010. 19.7-9 : 911-913.

16. Chiu, K.C., et al. , Journal of applied physics 1996. 79.3 (1996): 1784-1787.

17. Bhattacharyya, S., et al. , Applied Physics Letters 2001. 79.10 : 1441-1443.

18. Nagano, A., et al. , Diamond and related materials 2008. 17.7-10 : 1199-1202.

19. Zapol, P., et al. , Physical Review 2001. B 65.4 : 045403.

20. Badziag, P., et al. , Nature, 1990. 343.6255 : 244-245.
21. Ohmagari, S., et al. , Journal of Nanomaterials 2009. 2009

22. Díaz, J., et al., Physical Review 2001. B 64.12 : 125204.

23. Chen, Y.-F., Surface science 1997. 380.2-3 : 199-209.

24. Diaz, J., et al., Physical Review 1996. B 54.11 : 8064.

25. Popov, C., et al. , Diamond and Related Materials 2004. 13.11-12 : 2071-2075.

26. Bourgoin, D., et al. , Thin Solid Films 1999. 357.2 : 246-253.

27. Cheung, T.T.P., Journal of Applied Physics 1982. 53.10 : 6857-6862.

28. Stöhr, J., NEXAFS Spectroscopy. Springer, Berlin, Heidelberg, 1992. . 114-161.

29. Outka, D.A., et al. , The Journal of chemical physics 1998. 88.6 : 3539-3554.

30. Al-Riyami, S., et al. , Diamond and related materials 2010. 19.5-6: 510-513.

31. Al-Riyami, S., et al. , ECS Transactions 2013. 50.22: 41.

32. Al-Riyami, S., et al., ECS Journal of Solid State Science and Technology 2013. 2.11 : M33.

33. Kanda, K., et al. , Diamond and related materials 2008. 17.7-10 : 1755-1758.

34. Guo, J.-H., et al. , Journal of electron spectroscopy and related phenomena, 1999. 101 : 551-554.

35. Jiménez, I., et al. , Physical Review 2000. B $62.7: 4261$.

36. Al-Riyami, S., et al., Applied Physics Express 2010. 3.11 : 115102.

37. Ohmagari, S., et al. , Japanese Journal of Applied Physics 2012. 51.2R : 025503. 